\title{
BIODIVERSITY OF HYDROCARBON-PRODUCING MICROALGAE FROM OIL CONTAMINATED IN COASTAL ZONE OF BATAM ISLAND
}

\author{
Dwi Susilaningsih $^{1^{*}}$, Marlinang Diarta Siburian ${ }^{1}$ and Tutik Murniasih ${ }^{2}$ \\ ${ }^{1}$ Research Centre for Biotechnology, Indonesian Institute of Sciences \\ J1 Raya Bogor Km. 46 Cibinong, Bogor 16911 - Indonesia \\ ${ }^{2}$ Research Centre for Oceanography, Indonesian Institute of Sciences \\ Jl. Pasir Putih 1, Ancol Timur, Jakarta. 14430, Indonesia \\ *e-mail: dwisusilaningsih@yahoo.com
}

\begin{abstract}
Addressing to the environmental and energy crises in Indonesia, the new alternative of green-economicenergy sources is required. In this study marine microalgae were isolated from oil-polluted coastal zone in Batam Island for alternative energy sources. The research was carried out by collecting the sea water samples from several peninsulas of Batam Island. The abundance of microalgal diversity was observed. The isolation was done by capillary micropipette technique. The method of specific screening for hydrocarbon-producing microalgae was done using selected media, $\mathrm{CO}_{2}$ rate and light intensity period treatments. The results showed that the Cyanobacteria and diatom occupied the Batam's coastal waters. From the isolated samples, 11 strains positively deposit the hydrocarbon in their cells. Further study for determining the isolates and their properties is still in progress.
\end{abstract}

Keywords: Bioenergy, Hydrocarbon, Marine, Microalgae, Oil spill polluted

\section{INTRODUCTION}

Batam coastline has been contaminated by petroleum spillage for many years due to the tanker accidents and wastes from anthropogenic activities. Petroleum containing hydrocarbons was famous for its difficulty recalcitrant to degrade, carcinogenic to human being and destruct the ocean ecology and biodiversity. Petroleum defined as a viscous liquid mixture that contains thousand of compounds mainly consisting of carbon and hydrogen, which conveniently is classified into four groups of compounds: saturates (paraffin), aromatics, resins, and aspaltenes (Sugiura et al., 1997).

Naturally, the decomposition process of the hydrocarbons contaminants is by slow weathering due to the evaporation of the low-molecular-weight fraction, dissolution of the water-soluble compounds, mixing of oil droplets with seawater, photochemical oxidation, and biodegradation. Nowadays, research of the biodegradation enhancement of petroleum in the natural environment has been intensified. The degradation processes produces many degrade-compounds rich of carbon, which is ideal as the living substrate for microorganisms, include the microalgae (Kasai et al., 2003).

Microalgae are well known for their photosynthetic ability that stirs the primary food chain in the ocean, produces sources of bioactive and useful compounds, include the accumulation of petrol hydrocarbon. Many screening techniques and strategies are used to increase the friendly-hydrocarbon contain in the cell of microalgae, for instance by enrichment of the media using the fate-hydrocarbon source, nitrogen and phosphorus. Those evidences give an idea, in the oil spillage ocean must be hydrocarbonproducing microalgae are occurred. In this research, particularly, we were investigating the hydrocarbon producing microalgae from the oilcontaminated area in order to get the sustainable alternative energy sources. In addition, through the research, attempt to collect the microalgal culture in order to build the culture bank or microalgal 
library indigenous to Indonesian environments was made. Moreover, the biodiversity of marine tropical microalgae from Indonesia were explored.

\section{MATERIALS AND METHODS}

Bearing in mind the port function, five peninsula ports of Batam Island were chosen, these are Batu Ampar, Sekupang, Water Front, Kabil and Nongsa.

Sea water temperature, $\mathrm{pH}$, and salinity were determined using portable equipment. The microalgae was collected using the planktonnet with mesh size of $20 \mu \mathrm{m}$. Isolation technique was done by micro-pipetting direct technique, enrichment media and specific treatment for hydrocarbon and hydrogen producing microalgae.

The samples were inoculated in the specific media with $50 \mathrm{ml}$ of working cultures in the flask and wrapped with aluminium foil. The flasks were aerated with $100 \% \mathrm{CO}_{2}$ for 12 hours. Therefore, the samples were incubated at usual condition for algae. The survivor and dominant algae were isolated and purified.

Microscopy observations were done by the Light microscope (Nikon, Tokyo, Japan) and the electron microscope Shimadzu JEOL, Tokyo, Japan.

The molecular of $18 \mathrm{~S}$ rDNA and $16 \mathrm{~S}$ rDNA methods for identifying the strain was made following the Sekiguchi's protocol.

The extraction procedures and determination of lipid were made using the modified Bligh-Dryer methods (Bligh and Dryer, 1959). Dried lipid was liquefied with hexane and injected into HPLC system. HPLC condition use the column of TSK gel ODS-80Ts (Tosoh Corporation, Tokyo, Japan), mobile phase Acetonitrile: $10 \mathrm{mM}$ Phosphate buffer pH 2 (80:20), detection on $280 \mathrm{~nm}$ of UV detector.

\section{RESULTS AND DISCUSSION}

Batam waters is located in the Malacca strait, a junction between Singapore, Malaysia and Indonesia. The location was chosen because the Batam waters is the critical point of the Malacca Strait, being the gate for international transportation of petroleum from the oil-sources countries such as Saudi Arabia, Iraq, Iran and Kuwait to the user countries such as Japan, China and Korea. The available width of the strait for tanker movement is very narrow being only 550 $\mathrm{m}$ and the depth is of $23.5 \mathrm{~m}$. The place is very critical and in fact tanker accident often happened.

Various sampling areas of different environment condition are expected to give differences of microalgal diversity. Under the light microscopy observation, there is different number of microalgal biodiversity at Batam waters (Table 1). The dominancy of Cyanobacteria, Green algae and Diatomae (Fig.1) in small numbers provide illustration that the seawater has less of microalgal diversity. The stratum of division is depicting the

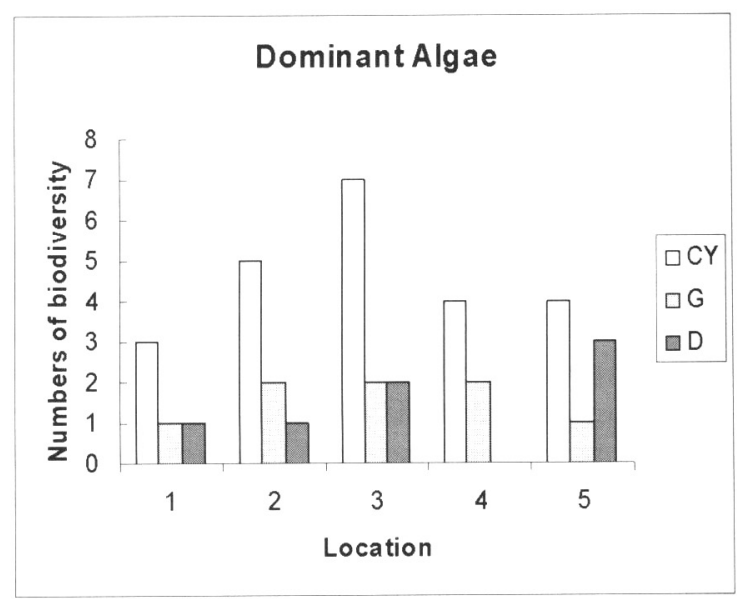

Figure 1. Three major dominant microalgae in Batam seawaters.

Note: Cy: Cyanobacteria, G: Green algae, D: Diatomae

area infertile and prosperous. Cyanobacteria are known for pioneer lower-plant that inhabitant of fresh, brackish, marine waters, rock and soil surface with condition the habitat are very limited/small light intensity and less sufficient of nutrient. Moreover, the diatomae usually dominated the areas that dirty/have pollutant or in eutrification phase (Codd et al., 1997). For instance, The Kabil port, where is heavily contaminated with oil spill from petroleum storage of PERTAMINA. At this port several of microalgal strains were hardly found, only Cyanobacteria and Green algae.

Three of Chlorophytes were prepared for morphological identification; they were suspected to be Tetraselmis sp., Chlorogonium sp., and Dyctyiophicea. The molecular data showed that the Chlorophyceae belong to Chlorogonium (1), Tetraselmis (2) and Chlorella saccharophyra (3). The total DNA was shown in Figure 2. The cyanobacteria were suspected as 
Table 1. Diversity of microalgae in the Batam seashore.

\begin{tabular}{|l|c|c|c|c|c|c|}
\hline \multirow{2}{*}{ Location } & \multicolumn{5}{|c|}{ Biodiversity } \\
\cline { 2 - 7 } & Cynobacteria & Chlorophytes & $\begin{array}{c}\text { Heteroconto } \\
\text { phytes }\end{array}$ & Dynophytes & Diatomae & Others \\
\hline 1. Batu Ampar & 3 & 1 & - & - & 1 & 1 \\
\hline 2. Sekupang & 5 & 2 & 1 & - & 1 & 2 \\
\hline 3. Water Front & 7 & 2 & - & - & 2 & 1 \\
\hline 4. Kabil & 4 & 2 & - & - & - & - \\
\hline 5. Nongsa & 4 & 1 & - & 1 & 4 & - \\
\hline
\end{tabular}

belong to Oscillatoriaceae, Nostocaceae or Arthospira. For further analysis, the molecular method was used and the total DNA obtained was shown in Figure 3.

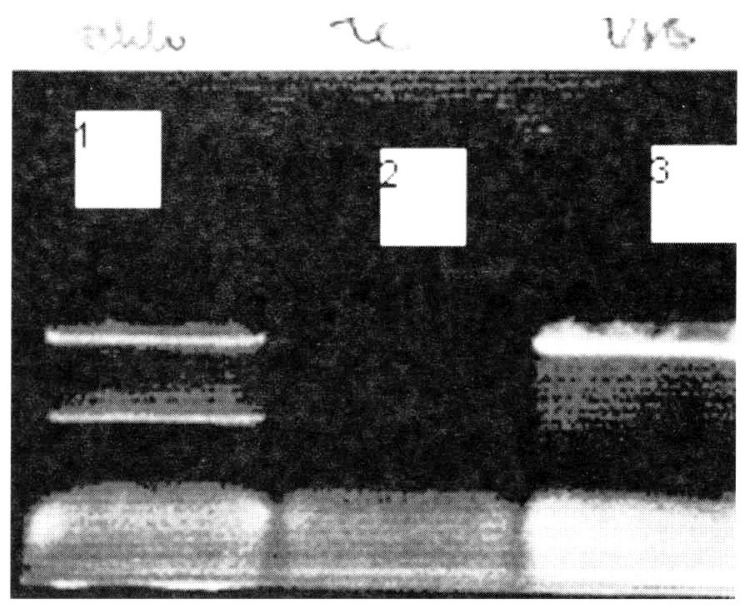

Figure 2. Total DNA of Chlorogonium (1), Tetraselmis (2) and Dyctiophyceae (3)

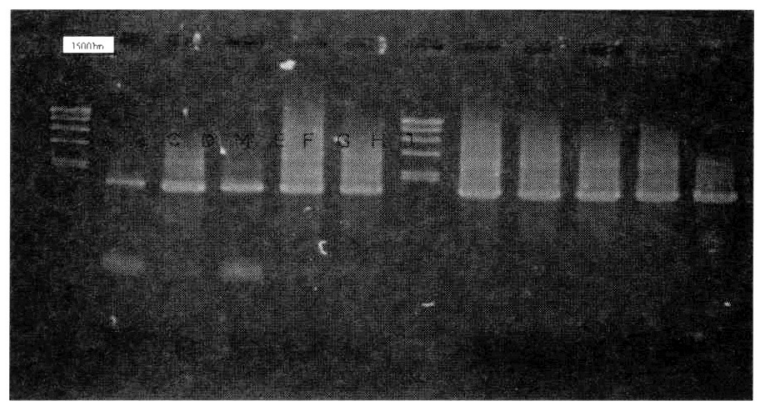

Figure 3. Total DNA of suspected Cyanobacteria Note: M; Marker. A, B, C, D, E, F, G, $\mathrm{H}, \mathrm{J}$; selected cyanobacteria.

Among the selected microalgae, ten isolates positively survive screening process. There are nine Cyanobacteria and one Chlorophyta. According to the Chromatography analyses, the fraction of carbon chain of the selected isolates were between $\mathrm{C} 16$ to $\mathrm{C} 32$ (Table 2). The results provide sign positively that the $m^{\circ} \mathrm{c}^{-}{ }^{1}$ gae from oil spill polluted seawater deposit lo carbon.
Table 2. Conversion of Chromatogram analysis of carbon content in the selected microalgae.

\begin{tabular}{|c|l|}
\hline \multicolumn{1}{|c|}{ Isolates } & Prediction carbon content \\
\hline 1. Green algae & C16-C32 \\
\hline 2. Cyanobacteria & \\
\hline A & C18-C24 \\
\hline B & C14-C22 \\
\hline C & C18-C25 \\
\hline D & C14-C18 \\
\hline E & C18-C24 \\
\hline F & C17-C23 \\
\hline G & C18-C24 \\
\hline$H$ & $\mathrm{C} 14-\mathrm{C} 18$ \\
\hline I & C12-C20 \\
\hline J & C16-C22 \\
\hline
\end{tabular}

Base on the HPLC data analyses the microalgae have several peaks similar with the commercial hydrocarbon. The data gives evidence that the selected microalgae positively produces the hydrocarbon (Fig. 4). Moreover, the comparison of the peak heights and the retention time of hydrocarbon fraction by HPLC analyses are showed in Figure 5. Some of the fraction of selected cyanobacteria of $\mathrm{A}$ and $\mathrm{E}$ are candidate high yield of specific hydrocarbon chains content (between C14-C20). In addition, other selected cyanobacteria also exhibited the specific hydrocarbon fraction, for instance the cyanobacteria strain F-J has unpredicted fraction of hydrocarbon chain in position of 25-35 minutes of retention time exposure.

In fact, the screening process is conduct to hydrocarbon storage and capability of oxygenic or an-oxygenic photosynthesis. The survivor of the screening process is expected to be able to produce hydrogen, instead of hydrocarbon. In this result shown only the cyanobacteria mostly can survive through the screening process, maybe we have to 

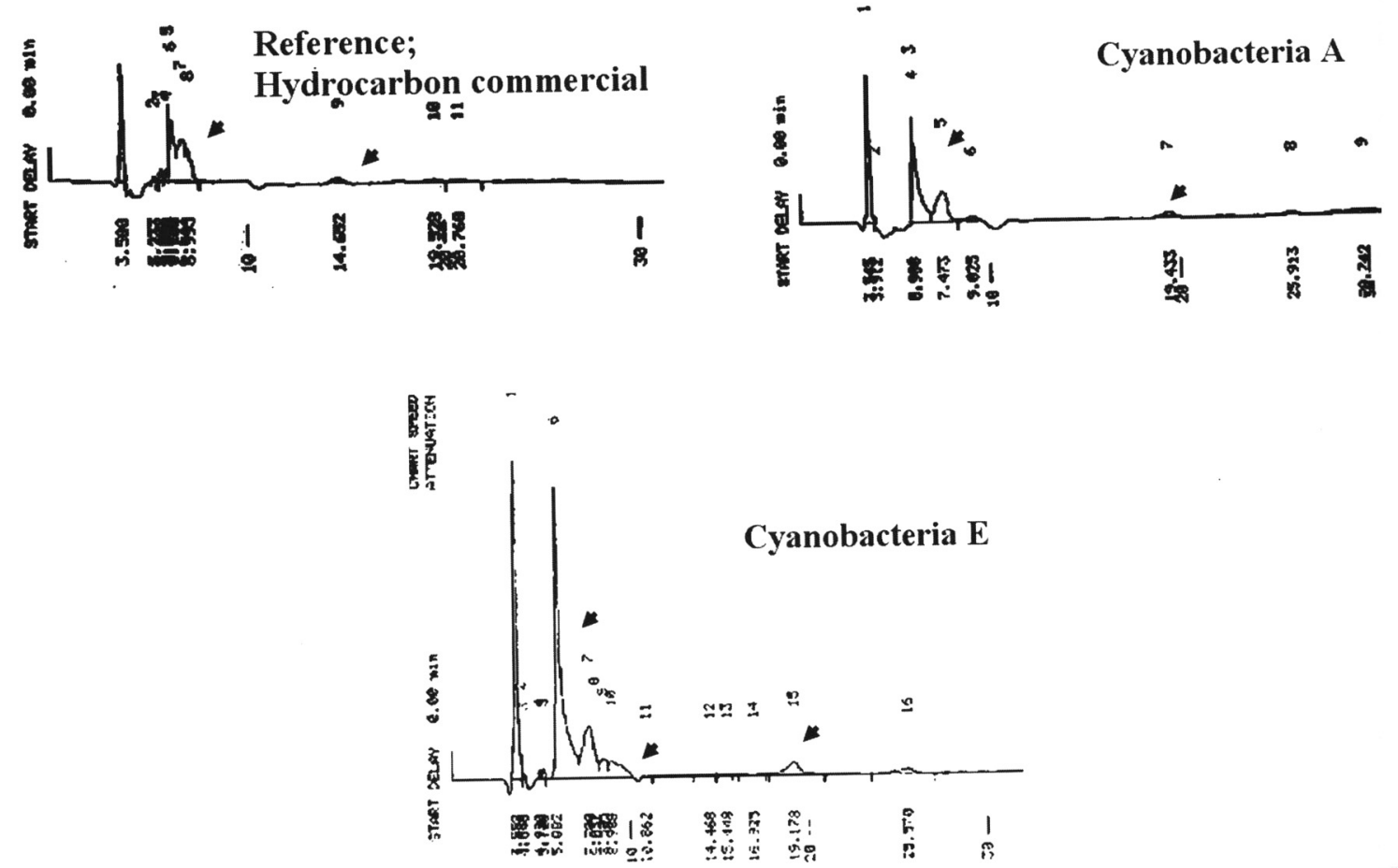

Figure 4. The HPLC chromatogram of number A and E compared to commercial hydrocarbon.

\section{Hydrocarbon fraction by HPLC Analysis}

\section{Cyanobacteria E}

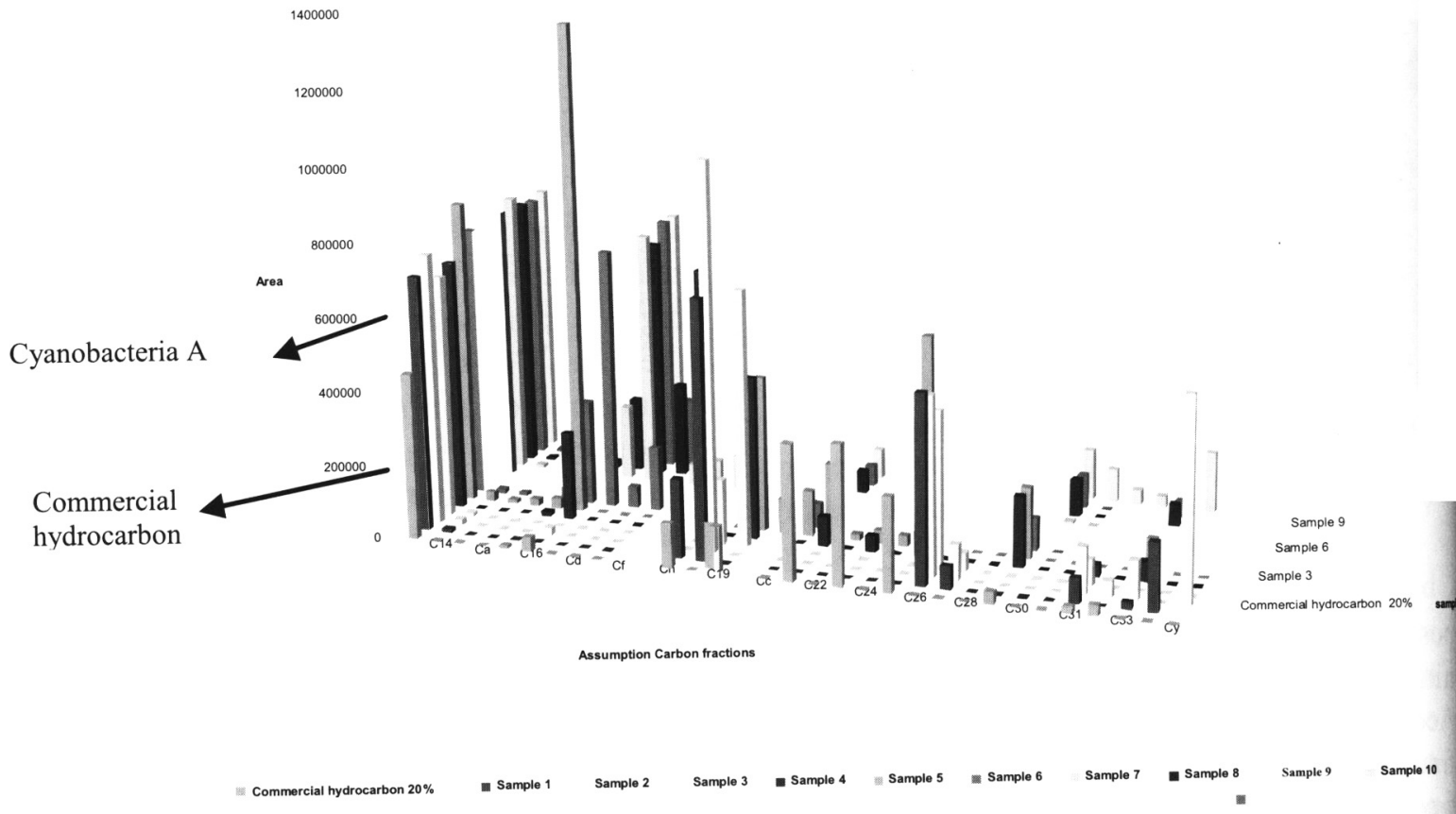

Figure 5. The prediction of hydrocarbon contain in the selected cyanobacteria compare to the commerci hydrocarbon. 
improve the screening procedures and the enrichment methods. We have expectation the hydrocarbon producing microalgae from tropical marine sources should revealed by diatomae, chlorophytes or heterocontophytes group, but we could not get it. In the next work plan we have to change the strategies for broaden the obtained microalgae collection in purpose.

Study the secondary metabolites from microalgae are fascinating, there are many things new and unpredicted. Microalgae have yielded new types of structures not found in higher plants or other bioactive compounds sources. Nowadays, there are great number of structure with the unique biological activity have been found from microalgae, in particular cyanobacteria (Susilaningsih et al., 2001). Cyanobacteria are the microorganisms between prokaryotes and eukaryotes that their metabolites, macro morphology, life style and environmental roles are not so different from eukaryotic microalgae. Simply stated, the biogenesis of secondary metabolites in microalgae is an unpredicted phenomenon. This research just began in the first year, hopefully, we can develop the research broadly more and continuously, in order someday we will have microalgal library indigenous Indonesia.
Acknowledgement. The research is partly funded by the Indonesia Toray Science Foundation fiscal years 2006, to which great appreciation is due.

\section{REFERENCES}

Bligh, E.G., and W.J. Dyer. 1959. A rapid method of total lipid extraction and purification. Canada Journal of Biochemistry and Physiology, 37: 911-917.

Codd, G.A., C.J. Ward, and S.G. Bell. 1997. Cyanobacterial Toxins: Occurrence, Modes of action, Health Effects and Exposure Routes. Archives of Toxicology Supplement, 19: 399-410.

Kasai, Y., K. Shindo S. Harayama, and N. Misawa. 2003. Molecular characterization and substrate preference of polycyclic aromatic Hydrocarbon Dioxygenase from Cycloclasticud sp. strain A5. Applied and Environmental Microbiology, 69 (11): 6688-6697.

Sugiura, K., M. Ishihara, T. Shimauchi, and S. Harayama. 1997. Physicochemical properties and biodegradability of crude oil. Environmental Science \& Technology, 31(1): 45-51.

Susilaningsih D., K. Hirata, Y. Asada, and K. Miyamoto. 2001. Utilization of cyanobacterial biomass from water bloom for bioproduction of lactic acid. World Journal of Microbiology \& Biotechnology, 17: 259-264.

Yuzuru, S. 1996. Microalgal metabolites: Anew perspective. Annual Review Microbiology, 50: 431-465. 